\title{
LA IMAGEN DE LA FAMILIA EN LA PRENSA RELIGIOSA DE MURCIA EN LOS INICIOS DEL SIGLO XX*
}

\author{
POR \\ Francisco JaVier CREspo SÁnchez \\ Universidad de Murcia
}

\section{RESUMEN}

En el inicio del siglo xx, Murcia será ejemplo del proceso de consolidación de la prensa católica de provincias. Transmisora de las ideas de la capital, la Iglesia utilizará este medio para promocionar su modelo ideal de familia en la sociedad en una etapa de marcada conflictividad social y política. A través de los artículos recogidos en la prensa, comprobaremos la construcción y difusión de un discurso basado en la perpetuación de la familia cristiana en el hogar, la exaltación del matrimonio y la definición del rol de los cónyuges.

PALABRAS ClAVE: Prensa, familia, hogar, matrimonio, religión, Iglesia.

\section{THE IMAGE OF THE FAMILY IN THE RELIGIOUS PRESS OF MURCIA IN THE EARLY XX CENTURY}

\begin{abstract}
In the early twentieth century, Murcia will be an example of the consolidation of the Catholic press in the provinces. As a transmitter of the ideas of the capital, the Church will use this media to promote their ideal model of family among the people in a time of remarkable social and political conflicts. Through the articles in the press, we will see the construction and dissemination of a discourse based
\end{abstract}

\footnotetext{
*Este trabajo se inscribe dentro del Programa de Becas de Formación del Profesorado Universitario del Ministerio de educación AP2009-0427, en el Proyecto de Investigación 11863/PHCS/09: El legado de los sacerdotes. El patrimonio del clero secular en Castilla durante el Antiguo Régimen, financiado por la Fundación Séneca: Agencia Regional de Ciencia y Tecnología de la Región de Murcia y en el Proyecto de Investigación HAR 2010-21325-C05-01 Realidades familiares hispanas en conflicto: de la sociedad de los linajes a la sociedad de los individuos, siglos XVII-XIX, financiado por el Ministerio de Economía y Competitividad.
} 
on the perpetuation of the Christian family at home, the exaltation of marriage and the definition of the role of the spouses.

KEY WORDS: Press, family, marriage, home, religion, Church

$\begin{array}{ll}\text { Recibido/Received } & \text { 07-03-2012 } \\ \text { Aceptado/Accepted } & 01-05-2014\end{array}$

Familia e Iglesia han sido y son dos instituciones de una gran tradición e importancia a lo largo de la historia de España, de forma que, para poder entender muchas de las realidades que llegan hasta nuestros días, es fundamental conocer su interrelación. De ahí que este estudio pretenda analizar el discurso manifestado por la Iglesia con respecto a la familia, centrándolo en la Murcia de comienzos del siglo xx y utilizando como fuente la prensa religiosa. ${ }^{1} \mathrm{La}$ familia se configurará como un elemento importante para conseguir y mantener el control a nivel social; considerada de vital importancia desde la ideología católica, su estudio nos proporcionará toda una serie de información sobre la conflictividad social que se genera en dicho periodo. Por ello, la intención última de este trabajo será comprender la evolución del discurso eclesiástico sobre la familia a través de la prensa y su posterior reflejo en el marco general de la sociedad.

Para centrar el tema propuesto resulta interesante analizar cuál será el modelo teórico propuesto para la familia cristiana por parte de los escritores católicos, comprobar si seguía respondiendo a los cánones ya presentados desde tiempos anteriores o si, por el contrario, se caracterizaba una nueva familia cristiana adaptada a los nuevos tiempos y realidades surgidas con el siglo xx. No sólo las nuevas situaciones matizadas por las corrientes laicistas y anticlericales modificarían la vida cotidiana de la familia, sino que la aparición del movimiento obrero, el alzamiento de las primeras voces del feminismo o el inicio de la organización de movimientos de mujeres católicas, ${ }^{2}$ serían realidades que fluían sobre la familia. De este modo, a través del análisis de los discursos recogidos en la prensa, podemos medir la evolución o permanencia de la ideología eclesiástica; al tiempo que comprobamos los niveles de recepción y resistencia que ofrecerá la sociedad del momento.

\footnotetext{
${ }^{1}$ Se trata de analizar la relación existente entre familia, Iglesia y prensa, el denominado como «conflicto triangular», concepto ya enunciado por Poulat, E. 1977. Catholicisme, démocratie et socialisme. Paris: Casterman.

${ }^{2}$ Estudiado en Blasco Herranz, I. 2002. «Tenemos las armas de nuestra fe y de nuestro amor y patriotismo; pero nos falta algo. La Acción Católica de la Mujer y la participación política en la España del primer tercio del siglo XX». Historia Social 44: 3-20; Mira Abad A. y Moreno Seco, M. 2004. «Maternidad y evolución de la identidad femenina en la España del siglo XX», en M. Santo (Coord.), $\mathrm{La}$ historia de las mujeres: una revisión historiográfica: 315-334. Valladolid: Universidad de Valladolid.
}

Hispania Sacra, LXVI

134, julio-diciembre 2014, 733-765, ISSN: 0018-215X, doi: 10.3989/hs.2014.067 
¿Fue la prensa el nuevo canal de expresión para hacer llegar a la masa social las preocupaciones de la Iglesia católica? Para responder a esta pregunta debemos comprobar si la Iglesia, a través de la prensa y focalizando sus energías en la familia, mostró nuevos signos de combatividad y reacción frente a las nuevas doctrinas que ponían en peligro su incuestionado control social. Siguiendo con esta argumentación, y estando de acuerdo con lo señalado por Longares Alonso de que a mitad del siglo xIx la prensa católica ya puede considerarse conformada, ${ }^{3}$ hay que plantearse si, con el nuevo siglo, la Iglesia intensificó el uso de la prensa como una de las más eficaces herramientas de difusión para hacer llegar su doctrina (junto a las ya tradicionales del púlpito y el confesionario) y tratar de mantener su posición dominante en el seno de la sociedad.

Para ello, a través de la prensa se argumentará la razón de ser de la familia como uno de los pilares de la religión católica. Al mismo tiempo, se defenderá una estructura familiar jerárquica, por lo que se atenderá a los distintos roles que debían desempeñar cada uno de los miembros de la misma. En este caso, nos centraremos de forma más contundente en las relaciones entre los esposos, caracterizando los papeles que debían desempeñar el marido y la mujer. Evidentemente, para ambos se reservarán funciones diferentes, siendo además más numerosa la información contenida con respecto a la mujer, ya que se tratará de controlar más a ella que al hombre, pues no debemos olvidar que se trata de un mundo confeccionado por y para el sexo masculino. De otro lado, no podemos obviar que el mensaje eclesiástico tendrá más incidencia en el mundo femenino, pues serán más receptivas a las palabras de los sacerdotes, acudirán en mayor número a las celebraciones eclesiásticas y frecuentarán más el confesionario que los hombres.

De otro lado, la elección del territorio murciano para el análisis de estas cuestiones responde al interés de estudiar si desde la capital, Madrid, se transmitían una serie de ideas hacia las provincias, algo más que plausible dado que muchos diarios ejercerán la práctica de reproducir noticias insertas en periódicos nacionales. Se trataría entonces de comprender y estudiar la difusión de ideas hacia la periferia desde el centro, que se convertirá en el eje director de la ideología que llega a los territorios más alejados. Además, el caso murciano presenta una serie de elementos particulares, pues no sólo sus diarios se proyectan de forma importante hacia otras provincias cercanas, sino que ejercerá una gran influencia cultural y política como cabeza de un extenso territorio. Esta experiencia será similar a la de otras provincias españolas, que sufren un proceso parecido con

${ }^{3}$ Longares Alonso, J. 1978. «Los canales de difusión de ideas en los comienzos del liberalismo español», en M.Andrés et al., Aproximación a la Historia social de la Iglesia Española contemporánea: 171-173. San Lorenzo de El Escorial: Ed. Biblioteca «La Ciudad de Dios» Real Monasterio de San Lorenzo de El Escorial. 
respecto a la prensa entre el final del siglo xIX y los inicios del siglo Xx. Murcia representa un ejemplo fuerte de desarrollo de la prensa católica de provincias, más si tenemos en cuenta que se trata de una sociedad con un marcado carácter religioso, sobre todo en lo que al culto exterior y a la coincidencia con el punto de vista de la Iglesia se refiere. En estos casos, la prensa se convertirá en portavoz de las élites existentes, grupos que representan en cierta forma el modelo familiar eclesiástico, ya que se quería ver reflejado en ellos a los guardianes de la pureza de las costumbres y el espejo en el que debían mirarse las clases inferiores. ${ }^{4}$

Por tanto, no se trata sólo de entender el modelo y analizar la doctrina, sino que se pretende conocer las razones del mismo y su reflejo en la sociedad, medir el grado de reacción de la Iglesia y comprobar si detrás de la argumentación religiosa de la familia se escondía un intento de seguir manteniendo su preeminencia en la sociedad. Para ello, será necesario en primer lugar atender al contexto en el que se desarrolla todo este proceso al que venimos refiriéndonos.

\section{LA IGLESIA EN UNA ÉPOCA CONFLICTIVA}

a nadie escapa que la llegada del nuevo siglo en España fue más que problemática, así entre 1899 y 1902 se produce la reincorporación del tema religioso a la primera línea de los programas políticos nacionales. No cabe duda que uno de los aspectos más tratados fue el de la limitación y sumisión de las órdenes y congregaciones religiosas. Todo ello se matizará en una etapa de marcada agitación política y religiosa, apuntalada por manifestaciones de tipo anticlerical, abundantes negociaciones con el Vaticano, la introducción de la cuestión religiosa en el marco legislativo y la utilización de la prensa como instrumento por parte de los diversos actores protagonistas de estos sucesos. ${ }^{5}$

El aspecto social y el aspecto político no quedarían separados el uno del otro en este contexto, de ahí que se haya planteado la idea de que la realidad de la sociedad se desarrollara más rápidamente que su sistema político. Por ello se ha expuesto que la distancia entre ambos se hizo evidente conforme avanzaba el tiempo, concretándose dicha lejanía en la separación entre la «España real» y

\footnotetext{
${ }^{4}$ Estudiado en Pérez-Picazo, M. T. 1986. Oligarquía urbana y campesinado en Murcia 1875-1902: 335-337. Murcia: Academia Alfonso X el Sabio.

${ }^{5}$ Para el conocimiento de la Iglesia en España en este periodo, se pueden consultar: Andrés-Gallego, J. 1975. La política religiosa en España, 1889-1913. Madrid: Editora Nacional; Benavides, D. 1978. Democracia y cristianismo en la España de la Restauración, 1875-1931. Madrid: Editora Nacional; Lannon, F. 1990. Privilegio, persecución y profecía La Iglesia católica en España, 1875-1975. Madrid: Alianza; Andrés-Gallego J. y Pazos, A. M. 1999. La Iglesia en la España contemporánea, 1800-1936. Madrid: Encuentro; Callahan, W. J. 2003. La Iglesia católica en España (1875-2002). Barcelona: Crítica.
}

Hispania Sacra, LXVI

134, julio-diciembre 2014, 733-765, ISSN: 0018-215X, doi: 10.3989/hs.2014.067 
la «España oficial». ${ }^{6}$ Por supuesto, el aspecto religioso no quedaría tampoco al margen de todo este proceso; así, dentro del marco político de la Restauración, una de las preocupaciones de la Iglesia sería la de recuperar la posición ocupada durante la etapa isabelina. De otro lado, si observamos la realidad existente ya en la segunda mitad del siglo XIX, comprobaremos como ya se adivinaba una postura dual en el seno interno de la Iglesia, ya que mientras que de un lado se buscaba conseguir el apoyo civil, desde el otro, se practicaba un cierto inmovilismo social. Por todo ello, la realidad social de la España a la que nos referimos presenta una serie de características particulares, tanto es así, que autores como Juan María Laboa consideran que la Nación desprendía una imagen que parecía más conservadora frente a lo que realmente era, ya que por ejemplo, la Iglesia se encontraba más anclada en el pasado que la propia clase dirigente. ${ }^{7}$ De esta forma, se estaba dando una ausencia evidente de un catolicismo de corte liberal, lo que en última instancia supuso una menor renovación y debate interno.

Todo este contexto de agitación vino acompañado por la presencia de los movimientos y de los sentimientos del anticlericalismo, que supondrán un nuevo elemento que participará en un contexto de conflictividad social y que repercutirá en la configuración de la relación existente entre la Iglesia y el mundo obrero. ${ }^{8}$ Postura que vendrá condicionada por la asociación que se realizará entre dicha conflictividad y el surgimiento de los primeros movimientos organizados de obreros, cuestión de vital importancia para entender todo su posterior desarrollo. En opinión de Castillo, el anticlericalismo de base obrera en la España del siglo xx es una reacción de tipo social a una actuación reaccionaria y antisocialista por parte de algunas organizaciones que se autotitulaban como católicas y que eran apoyadas por la jerarquía eclesiástica. ${ }^{9}$

Ante dicha situación, la Iglesia reaccionará frente a lo que consideraba la «desacralización del mundo moderno», proceso que traería consigo el derrumbamiento de instituciones jurídicas que hasta el momento habían tutelado la presencia del clero en los puestos rectores de la vida social. De ahí que la libertad religiosa fuera uno de los elementos a combatir junto a la aproximación al mundo

${ }^{6}$ Gay Armenteros, J. C. 2005. «La lucha por la opinión pública en Granada hasta el franquismo», en J.-L. Ruiz Sánchez (Coord.), Catolicismo y comunicación en la historia contemporánea: 15. Sevilla: Universidad de Sevilla.

${ }^{7}$ Laboa, J. M. 1994. La Iglesia del siglo XIX. Entre la Restauración y la Revolución: 286. Madrid: Publicaciones de la Universidad Pontificia Comillas.

${ }^{8}$ Aspecto analizado en diversas obras como La Parra López, E. y Suárez Cortina, M. (Eds.) 1998. El anticlericalismo español contemporáneo. Madrid: Biblioteca Nueva; Pérez Ledesma, M. 2001. «Anticlericalismo y secularización en España», en A. Morales Moya (Coord.), La cultura. Las claves de la España del siglo xx: 269-285. Madrid: España nuevo milenio; De La Cueva J. y Montero F. (Eds.) 2007. La secularización conflictiva. España (1898-1931). Madrid: Biblioteca Nueva.

${ }^{9}$ Castillo, J. J. y Vilar, P. 1977. El sindicalismo amarillo en España: aportación al estudio del catolicismo social español (1912-1923): 53. Madrid: Cuadernos para el diálogo. 
moderno y sus errores. Al condenar al mundo moderno, se daba a este elemento de combate una perspectiva de fondo, pues la jerarquía eclesiástica culparía a la ley y a las reformas legislativas de la maldad del mundo, por lo que era necesaria una acción de los católicos dirigida a la conquista del poder legislativo y de la opinión pública. Para conseguir sus propósitos, dos serán las consecuencias inmediatas dentro de este proceso por el cual la Iglesia quería recuperar su puesto rector: la instrumentalización negativa del laicado y la politización de la Iglesia. ${ }^{10}$

Fruto de este proceso de politización eclesiástica, podemos decir que, tras el intervalo anteriormente citado (1899-1902) y durante los doce años comprendidos entre la vuelta de Sagasta al poder y el asesinato de José Canalejas, presidente del gobierno en 1912, el debate sobre el clericalismo se hizo más intenso que nunca. Todo ello, ante toda una serie de nuevas cuestiones que estaban provocando que el sistema ideado por Cánovas afrontara nuevos retos: la aparición de un fuerte movimiento autonomista en Cataluña, el auge de los nuevos sectores del republicanismo o la serie de problemas económicos que contribuyeron al malestar social durante el primer decenio del siglo. ${ }^{11}$

La convivencia entre la Iglesia y el Estado fue particularmente difícil durante el segundo lustro del siglo xx puesto que los sucesivos gobiernos de Sagasta, Maura, Montero Ríos, Moret y del general López Domínguez no lograron rebajar la tensión. ${ }^{12}$ La consecuencia fue un evidente proceso de politización eclesiástico que alcanzará su punto culminante durante el gobierno de Antonio Maura entre 1907 y 1909 - solución conservadora ante la escalada de tensión que se había producido con los gobiernos anteriores - ya que la jerarquía eclesiástica pasó desde una postura de neutralidad política a otra de apoyo activo a Maura. Por ello, durante los dos años y medio que permaneció en el poder, el presidente del gobierno recibió el apoyo creciente del clero y el laicado católico, ya que veían en él, en términos prácticos, a la única figura capaz de bloquear los planes del Partido Liberal relativos a la Iglesia y de frenar el republicanismo anticlerical.

Durante los sucesos de la Semana Trágica, los obreros centraron sus iras sobre iglesias y clero. La institución católica vio estos ataques como el resultado de una conspiración planeada por los anticlericales ante la debilidad del Estado liberal. ${ }^{13}$ Tras los sucesos, se reforzó la visión de la Iglesia como baluarte del orden social, identificándose con más fuerza con la monarquía alfonsina y el ejército. Así, en 1910 la Iglesia ya se había perfilado como un poderoso grupo de interés comprometido con la defensa del orden social, la monarquía y el ejército. De esta forma, su proceso de reconquista de los espacios sociales, aunque

\footnotetext{
${ }^{10}$ Andrés-Gallego, J. 1975: 510.

${ }^{11}$ Callahan, W. J. 2003: 59-79.

${ }^{12}$ Andrés-Gallego, J. 1975: 241-257.

${ }^{13}$ Callahan, W. J. 2003: 75.
} 
fuera en el plano teórico, comenzaba a dar sus primeros frutos. Buena prueba de ello es que las reformas de Canalejas entre 1910 y 1912 al final sólo impusieron limitaciones de poca importancia a los privilegios de la Iglesia, pero el clero y sus seguidores dieron rienda suelta a la retórica y organizaron manifestaciones públicas. Cuando murió el presidente, la polémica en torno a la Iglesia había comenzado a disminuir, pues sus intentos de resolver la cuestión del lugar de la institución dentro de la monarquía constitucional no fueron más afortunados que los de sus predecesores.

Aunque se dio una cierta relajación de la «cuestión religiosa», la época posterior a Canalejas empezó con otra lucha entre un ministerio liberal y la Iglesia. La decisión del nuevo presidente, Romanones, de obligar a ciertos miembros de órdenes religiosas a cumplir el servicio militar, junto a otros temas, generó grandes protestas, utilizando como portavoces los mítines públicos o el diario católico El Debate. El conflicto puso de manifiesto que la Iglesia y sus partidarios poseían aún influencia suficiente para bloquear los cambios importantes.

Mientras tenían lugar los acontecimientos de la crisis de 1917, la voz de la Iglesia permaneció curiosamente callada. ${ }^{14}$ El clero se dio cuenta que los sucesos de las Juntas Militares, el movimiento asambleario y la huelga general habían provocado una crisis total en España, tema recurrente en periódicos y revistas católicas. Varios factores explican esta reacción cautelosa: la Iglesia no resultó atacada directamente durante la agitación política y social, la violencia de la huelga general no apuntó hacia la Iglesia como en el caso de la Semana Trágica y gran parte de la opinión católica vio la crisis de 1917 como un hecho positivo en sus dimensiones políticas. ${ }^{15} \mathrm{~A}$ pesar de las esperanzas de que la prolongada crisis de 1917 y principios de 1918 causara cambios en el régimen que lo hiciera más sensible a los intereses clericales, el monopolio de los partidos dinásticos, muy fragmentado ya, sí ayudó a mantener el orden establecido hasta el momento.

La oleada de huelgas sucedidas en 1919 dio lugar a respuestas distintas por parte de los gobiernos: desde la total represión hasta los tímidos intentos de reconciliación. Desde la jerarquía eclesiástica se dejó ver la degradación moral y barbarie que castigaba al pueblo español; por ello, en su discurso se manifestaba que el mantenimiento del orden social era lo más importante, ya que temían más que nunca una revolución social. La serie de conflictos fueron vistos como un enfrentamiento entre la civilización cristiana y las hordas revolucionarias

\footnotetext{
${ }^{14}$ Espadas Burgos, M. 1983. «La Iglesia española y la primera guerra mundial», en M. Espadas Burgos (ed.), Iglesia, sociedad y política en la España contemporánea: 131-158. El Escorial: Ediciones Escurialenses.

${ }^{15}$ Incluso una revista clerical afirmó que «aún aquellos partidos políticos que llevan en su programa histórico los principios del laicismo guardan hoy sobre esos puntos cierto significativo silencio»; $\mathrm{La}$ ciencia tomista, 16, 1917, 404.
} 
que querían destruirla, visión reforzada desde la prensa. Además, la incapacidad de los gobiernos liberales, conservadores o de coalición, para aplastar la agitación social entre 1917 y 1922 hizo desaparecer los vestigios de confianza que la Iglesia y la opinión católica tenían depositada en la Restauración. Al mismo tiempo, el desastre de Annual tuvo un doble efecto en la Iglesia: reforzó el compromiso con el ejército por parte de los obispos y confirmó la antigua creencia de que el sistema liberal había provocado la ira divina por llevar a España por el camino de la inmoralidad, ya señalado desde el desastre de $1898 .^{16}$

Así, en 1922 el entendimiento entre la Iglesia y el Estado liberal empezaba a tambalearse. Aunque las cosas no le habían ido mal a la Iglesia durante la Restauración, este sistema político ya había perdido utilidad para la Iglesia. La relación entre los mundos civil y eclesiástico durante la Restauración fue ambigua y contradictoria, pero en cierta medida logró limitar las ambiciones clericales de influir en todos los aspectos de la vida política y social. Sin embargo, esta limitación estaba a punto de desaparecer con la llegada del nuevo régimen militar a España. La Iglesia colaborará con la dictadura, no obstante, podemos remarcar que obtuvo un escaso beneficio a pesar del apoyo manifestado a la misma, pues la relación entre ambos actores continuaba siendo difícil.

Se hace necesario también, al margen del contexto anterior y de forma breve, dar algunas pinceladas muy generales sobre el estado de Murcia en el tránsito del siglo XIX al Xx. Así, en lo que a la demografía se refiere, el crecimiento experimentado a finales de la centuria decimonónica tendrá continuación durante el primer tercio del siglo xx. Esto vino motivado por la alta natalidad y la emigración desde provincias cercanas, por lo que el territorio murciano experimentará un alto crecimiento poblacional. En cuanto a la economía se asistirán a una serie de transformaciones motivadas prioritariamente por la integración mercantil de la agricultura y de la elaboración agroalimentaria. No obstante, la economía se encontraba en una fase de transformación sustentada en un modelo basado en la exportación agrícola y el tímido despegue del sector industrial, acompañados a su vez de sectores como el curtido y el textil. Al mismo tiempo, la minería, la metalurgia y el sector industrial de Cartagena y su comarca no atravesarán su mejor etapa en estos momentos.

La sociedad, heredera de las clases existentes en el siglo anterior, presentará fuertes contrastes y una gran polaridad, con grupos hegemónicos que mantendrán una clara ideología conservadora, unas clases medias de tipo urbano que aún serán escasas y un campesinado similar al que se había conocido hasta entonces. En este ámbito, Iglesia y sector civil se entendieron de buen grado, llegando a una notable colaboración entre ambos; es decir, entre los sectores

${ }^{16}$ Como ha expuesto Callahan, W. J. 2003: 95.

Hispania Sacra, LXVI

134, julio-diciembre 2014, 733-765, ISSN: 0018-215X, doi: 10.3989/hs.2014.067 
eclesiásticos y las administraciones locales, como demuestra por ejemplo las subvenciones a las cofradías en Semana Santa. Sin embargo, entre la Iglesia y la población existía ya una distancia considerable, espacio que la Iglesia no supo reducir durante este periodo, aunque lo intentó, como así demuestran la creación de los diferentes Círculos Católicos y las distintas iniciativas llevadas a cabo por los mismos. En cuanto al desarrollo literario y artístico apenas si ofrece innovaciones, constante que se encuentra en consonancia con la situación existente: falta de consolidación de la burguesía, alto analfabetismo, la actitud provinciana de las masas y el alto nivel de ruralismo. Sin embargo, destacarán escritores como Díaz Cassou, Federico Balart, Ricardo Gil, Miguel Pelayo o Jara Carrillo. En lo que a la política se refiere, en Murcia la fuerza política más sólida era el Partido Conservador, que desde 1903 estuvo dirigido por Juan de la Cierva, aunque también contaría con la presencia de José Maestre, alcanzado grandes cotas de poder y control en la comarca. Mientras tanto, el Partido Liberal se encontraba más dividido y enfrentado en su fuero interno.

En resumen, podemos decir que partimos de un periodo convulso y cambiante, donde el debate y la dialéctica estarán presentes en la vida política del país. El otro vértice, el de la opinión pública y el de los espacios sociales, también será muy importante, por lo que la prensa se configurará como uno de los agentes importantes para su recuperación. Por ello, es necesario conocer el estado de la prensa, teniendo presente para este análisis que la tardía aceptación de este medio de difusión por parte del sector eclesiástico, jugaría un papel determinante en la posterior evolución del periodismo católico.

\section{El ESTADO DE LA PRENSA Y DEL PERIODISMO CATÓLICO}

La realidad periodística de España en los inicios del siglo xx queda matizada entre dos corrientes que hacen acto de presencia durante el tránsito entre este siglo y el anterior: de un lado encontramos los periódicos herederos del siglo XIX, caracterizados por ser seguidores de determinadas personalidades de importancia y por una gran carga ideológica, este tipo de periódicos tenían corta vida y escasa difusión. Del otro, los periódicos basados en la información y no tanto en el adoctrinamiento, con carácter empresarial y más profesionalizados que los anteriores. Estos diarios tuvieron una mayor tirada y perduraron más en el tiempo. ${ }^{17}$

\footnotetext{
${ }^{17}$ Para un análisis general de la prensa española: Espina, A. 1960. El cuarto poder. Cien años de periodismo español. Madrid: Aguilar; Gómez Aparicio, P. 1967. Historia del periodismo español. Madrid: Editora Nacional; Schulte, H.F. 1968. The spanish press 1470-1966: print, power and politics. Chicago: University of Illinois press; Sáiz, M. D. 1990. Historia del periodismo en España. Los orígenes. El siglo XVIII. Madrid: Alianza; Seoane, M. C. 1989. Historia del periodismo en España 2. El siglo XIX. Madrid: Alianza; Medina Arjona, E. 2009. La prensa/La presse. Jaén: Universidad de Jaén.
} 
El convulso panorama político se reflejará en una prensa que estará caracterizada, en líneas generales, por los siguientes periódicos: La correspondencia de España, El imparcial, El Liberal, Heraldo de Madrid y La Vanguardia. En este contexto, tendrán lugar dos momentos claves que alterarán el panorama general del periodismo español del momento: la aparición en 1905 de $A B C$ como periódico y la constitución, en 1906, de la Sociedad Editorial, lo que supuso un evidente cambio en la estrategia empresarial de la prensa española. ${ }^{18}$ Además, hay que señalar que se produjo un notable incremento de publicaciones a nivel provincial. ${ }^{19}$

Dentro de todo este proceso de cambio hay que indicar que pese a los primeros esfuerzos dedicados por los sectores católicos, los resultados no fueron los esperados, quedando claramente en un plano secundario con respecto a los obtenidos por los liberales. A la falta de recursos materiales e intelectuales, se añadió la ignorancia de las técnicas y de los recursos periodísticos, que en la época referida, podían ir en contra de algunos de los principios defendidos por la Iglesia. No obstante, la preocupación por la creación y desarrollo de un periodismo católico se dio en España de forma más tardía que en el resto de Europa. Fue durante la Restauración canovista cuando se sentaron las bases que propiciaron su desarrollo, una misión considerada como un nuevo apostolado en el que tenía que implicarse el clero. Las primeras publicaciones católicas tuvieron un carácter elitista y científico, dirigidas a un público selecto y minoritario, como demuestra el caso de La ciencia cristiana (1877). Además, el campo y labor de los propagandistas no quedó sólo en la prensa, sino que se utilizó un género más popular para las masas, las hojas parroquiales y los boletines. ${ }^{20}$

Dentro de este sistema también se daba una división clara entre los católicos que apoyaban al mismo y los que no lo aceptaban, motivo que provocaría que la llegada de un diario de amplia difusión se hiciera esperar. Predominó más una prensa de partido que defendía los planteamientos de la Iglesia, caso de $E l$ Fénix o La fe. Esta división de los católicos ante la prensa quedó patente a través de sus distintas posturas y enfrentamientos, pues cada grupo pretendía imponer su visión y hacía una lectura distinta de los escritos pontificios referentes a la prensa. Tampoco podemos olvidar otro suceso clave dentro del ámbito de la prensa católica en España: la celebración en 1904 en Sevilla de la I Asamblea

\footnotetext{
${ }^{18}$ Fuentes, J. y Fernández Sebastián, J. 1998. Historia del periodismo español: prensa, política y opinión pública en la España contemporánea: 171-173. Madrid: Síntesis.

${ }^{19}$ Botrel, J.-F. y Desvois, J.-M. 1991. «Las condiciones de la producción cultural», en S. Salaün y C. Serrano (eds.), 1900 en España: 43-48. Madrid: Espasa Calpe.

${ }^{20}$ Los estudios sobre prensa católica han sido numerosos: Hibbs-Lissorgues, S. 1995. Iglesia, prensa y sociedad en España (1868-1904). Alicante: Instituto de Cultura Juan Gil-Albert; Ruiz Sánchez, J.-L. 2002. Prensa y propaganda católica (1832-1965). Sevilla: Universidad de Sevilla; Romero Domínguez, L. 2009. La buena prensa. Prensa católica en Andalucía durante la Restauración. Sevilla: Centro de Estudios Andaluces.
}

Hispania Sacra, LXVI

134, julio-diciembre 2014, 733-765, ISSN: 0018-215X, doi: 10.3989/hs.2014.067 
Nacional de la Buena Prensa, configurándose ésta como la primera en que todos los implicados en el periodismo católico pudieron intercambiar su opinión. Dicha asamblea fue continuada posteriormente en las celebradas en Zaragoza (1908) y Toledo (1924), fruto de esta última se decidió la creación de la Junta Nacional de Prensa Católica. De esta forma se fue generando un moderno periodismo de empresa en torno a dos grupos rivales: el Trust, de signo liberal; y la Prensa Española, de signo conservador e impulsado por Luca de Tena. Ambas corrientes conviven con la prensa carlista y la prensa que apoyará a los distintos gobiernos de la Restauración.

Así, a principios del siglo xx y siguiendo las indicaciones del Papa León XIII, la Iglesia comenzó a tener voz propia en la prensa diaria española. Se dieron intentos fracasados de crear un gran diario católico, como fueron $\mathrm{El} \mathrm{uni-}$ verso y El movimiento católico. De esta forma, el núcleo de la prensa católica en su origen lo constituye El correo de Andalucía (Sevilla, 1 de febrero de 1899) ${ }^{21}$ A partir de ahí se desarrolló el movimiento de la Buena Prensa, y una red de publicaciones en las provincias, dando lugar a una sólida implantación regional posterior. No obstante, pese a los primeros fracasos para crear un gran periódico, se trabajó en otros campos, tomándolo como una especie de trabajo previo, basado en la denuncia, en la censura, en la prevención de la lectura, en la búsqueda de colaboración por parte de los sacerdotes y en la advertencia a los periodistas. ${ }^{22}$

La prensa católica no tendrá un representante de verdadera entidad hasta la creación en 1910 de El debate, donde tuvo un papel fundamental la Editorial Vizcaína en cuanto a lo que su fundación se refiere. Lo importante era que había que definir la posición de los católicos con respecto a la prensa, así, la pregunta capital era si los católicos necesitaban unos medios específicos para realizar su misión en el mundo o si por el contrario podían servirse de los diarios civiles ya existentes. No obstante, las labores asignadas al periodismo católico eran claramente superiores a sus fuerzas, ya que se esperaba que detuviera el proceso de secularización en las costumbres que azotaba a la sociedad española. Tenía también que intervenir en el plano de la política defendiendo los postulados de la Iglesia, a la vez que debía evitar la descristianización del mundo del trabajo. Muchos católicos pensaron que habían conseguido la herramienta para cambiar el mundo contemporáneo, pero ésta era una postura equivocada.

En definitiva, podemos decir que tras las primeras décadas del siglo xx, la presencia de los periódicos católicos de diversa índole y temática en el panorama

\footnotetext{
${ }^{21}$ Ruiz Sánchez, J.-L. (ed.) 2005. Catolicismo y comunicación en la historia contemporánea: 115116. Sevilla: Universidad de Sevilla.

${ }^{22}$ Estudiado en Pelaz López, J. V. 2000. Caciques, apóstoles y periodistas. Medios de comunicación, poder y sociedad en Palencia (1898-1939). Valladolid: Universidad de Valladolid.
} 
español ya era una realidad. Desde los primeros compases de negación y dificultad, se pasó a un panorama de aceptación y de difusión de grandes diarios católicos; muestra de ello será la presencia de diversos periódicos y revistas en las diferentes provincias y ciudades españolas, con títulos tan importantes como La gaceta del Sur en Granada, el anteriormente citado Correo de Andalucía en Sevilla, La lectura popular en Orihuela, La voz de Alicante en dicha provincia, la Gaceta del Norte en Bilbao, El noticiero en Zaragoza o El porvenir en Valladolid. ${ }^{23}$

Dentro de este proceso de consolidación de la prensa católica en las provincias, Murcia no quedó ajena. Destaca la presencia de periódicos heredados de los finales del siglo XIX como El noticiero, El diario, Las provincias, El heraldo de Murcia, El correo de Levante, La tribuna y algunas revistas literarias..$^{24}$ Además, la provincia vivirá en los inicios del nuevo siglo una época prolífica en lo que a publicaciones periódicas se refiere. En el bienio 1902-1903, el periodismo da el paso hacia una cierta modernidad, ya que se inicia un cambio para llegar a una nueva etapa. En 1902 finalizan Las provincias de Levante y en 1903 desaparecen El Heraldo y El correo de Levante. De otro lado, tenemos que citar la prensa informativa, marcada por dos grandes periódicos: El liberal (1902) y La verdad (1903), que inauguran un periodismo con mayor base informativa, más rico en noticias nacionales e internacionales. ${ }^{25}$

Por su importancia destaca La verdad (aparece por primera vez el 3 de marzo de 1903), vinculada al movimiento obrerista católico, su nacimiento se debe a la acción decidida del clero murciano y al apoyo de algunos industriales. Su origen se relaciona con el intento de contrarrestar la influencia de la prensa de izquierdas y de corte anticlerical. Se paliaba así una de las grandes carencias que presentaba el mundo eclesiástico a finales del siglo XIX como era la falta de activismo del periodismo católico. ${ }^{26}$ La verdad nació bajo un signo muy eclesial y de ahí que sus primeras campañas estuvieran vinculadas casi en su totalidad a lo religioso. Una de ellas fue a favor del descanso dominical, que en muchos

${ }^{23}$ Pascual Martínez, P. 2001. «Publicaciones periódicas eclesiásticas y religiosas de España entre los siglos XIX y XX». Hispania Sacra 107: 169-191.

${ }^{24}$ Como ha expuesto Crespo Pérez, A. 1986. La prensa periódica en la ciudad de Murcia (17061986): 53. Murcia: Caja de ahorros de Alicante y Murcia.

${ }^{25}$ Para el caso murciano encontramos desde los estudios más generalistas como son los de De Lara Fernández, F. y Fresneda Collado, R. 1996. Catálogo de publicaciones de la Región de Murcia (1876-1939). Murcia: Fundación Instituto de la Comunicación de Murcia; González Castaño J. 1996. La prensa local en la Región de Murcia (1706-1939). Murcia: Universidad de Murcia; hasta estudios más específicos como los de Alonso Navarro, S. 1987. Prensa murciana del siglo XIX: El Semanario Murciano, El Diario de Murcia, Heraldo de Murcia. Murcia: Asociación de la Prensa de Murcia; De Los Reyes, A. 1996. «La prensa murciana en el siglo XIX: una aproximación». Anales de Historia Contemporánea 12: 343-370.

${ }^{26}$ Robles Muñoz, C. 1989. «La diócesis de Cartagena durante la Restauración (1874-1900)». Murgetana 79: 69-105.

Hispania Sacra, LXVI

134, julio-diciembre 2014, 733-765, ISSN: 0018-215X, doi: 10.3989/hs.2014.067 
sectores no se cumplía; para dar ejemplo, los periódicos se comprometieron a no trabajar ese día, con excepción de El liberal que no aceptó el acuerdo. Otra de sus campañas hizo referencia al Entierro de la Sardina, fiesta que molestaba a la población según el periódico, pues eran mujeres de vida pública las tripulantes de las carrozas que en ellas desfilaban, por lo que se pedía mayor recato y moralidad para las mismas.

De esta forma, el panorama de la prensa católica en Murcia estuvo marcado por unas constantes que se repiten en el resto del territorio nacional: una lucha dialéctica con la prensa de corte liberal, la defensa de los intereses de la Iglesia Católica, toda una serie de dificultades en cuanto a lo que propagación se refiere y una escasa sensibilidad ante la utilidad de la prensa por parte de estos sectores católicos. ${ }^{27} \mathrm{Al}$ mismo tiempo, la situación parte desde dos supuestos: la jerarquía eclesiástica ejercerá un claro control sobre la prensa confesional y la escasa incidencia que logrará sobre los sectores proletarios.

La anteriormente mencionada Asamblea de la Buena Prensa y el Congreso de Burgos animaron a la creación de una serie de diarios católicos en la Región de Murcia, ya que dentro de su espíritu se encontraba la idea de fomentar dicha prensa y propiciar la unidad de los católicos. Algunas de estas publicaciones surgidas fueron El eco de Cartagena, La verdad de Murcia, El faro de la juventud, La gran cruzada moderna o El cruzado. En el impulso y origen de estas publicaciones católicas murcianas se encontraban diversos agentes y protagonistas. Así fue el caso del propio obispado, que a través de sus boletines dio buena cuenta de sus intenciones a la hora de crear una prensa católica. Para Murcia destaca especialmente la labor del Seminario de San Fulgencio, que dedicará grandes esfuerzos a la causa de la prensa. Algunas órdenes eclesiásticas, caso de los franciscanos, también participaron notablemente de la labor periodística de la época. No cabe duda de que algunas parroquias también ayudaron a la consolidación de estos periódicos, como así demuestra la salida de las diferentes hojas parroquiales. Otro de los medios a través de los que se impulsó la creación de periódicos religiosos fue la práctica de las colectas, no sólo las promovidas en la «Fiesta de la Buena Prensa», sino en las diversas campañas de propaganda que se incluían en los propios periódicos. Así, se exhortaba a las familias a colaborar económicamente con la creación de diarios y revistas. En muchas ocasiones estas donaciones procederán de acaudalados católicos, de la burguesía y de las clases conservadoras, que se vinculaban más con los planteamientos de orden y estabilidad católicos. Por otra parte, en la génesis de estos periódicos en Murcia

${ }^{27}$ La prensa católica murciana ha sido estudiada desde las obras de carácter más general: Victoria Moreno, D. 1981. «La prensa católica en la Región Murciana durante el primer tercio del siglo XX». Murgetana 61: 51-79; hasta las más específicas: Arroyo, M. 2000. «La prensa católica: La Verdad de Murcia (1903-1988)». Hispania Sacra 106: 541-554. 
también jugaron un papel destacado diversas organizaciones católicas que trataban de fomentar sus propios órganos de expresión: caso del Sindicato Católico Obrero y su periódico La Casa del pueblo, la Junta Diocesana (con diversas publicaciones) o la Asociación de Señoras de la Acción Católico-Social y Luz y amor. No obstante, más allá de la propia ciudad, el núcleo eclesiástico que más énfasis puso en la difusión periodística fue la iglesia arciprestal de Santa María de Gracia de Cartagena.

Si analizamos internamente el estado de la prensa católica en Murcia podemos comprobar que se diferencia bien entre los sectores de la prensa informativa y la de signo más combativo. ${ }^{28}$ No obstante, los lectores se inclinaron en su mayoría por la primera, siendo los diarios católicos más difundidos en la diócesis El debate y La verdad. En lo referente a la prensa de combate encontramos La Unión católica, La defensa de Murcia, La lucha o Alma joven. Dentro de estos sectores destacó Antonio Sánchez Maurandi, gran propagador del catolicismo social en la provincia. A pesar de la marcada religiosidad de la sociedad, los inicios de la prensa católica en Murcia contarán con toda una serie de dificultades, ya que tendrá pocos suscriptores, sumado todo ello a una importante escasez económica y de medios. Un ejemplo de esta situación lo encontramos en 1918 en el periódico El cruzado, que dejaba clara la realidad existente en su artículo «De nuestro certamen. Temas prácticos. Lema: vince teipsum». ${ }^{29}$ En este escrito exponía que las dificultades con que se tropezaba la propaganda de la Buena Prensa eran muchas e importantes, insistiendo en que incluso era imposible enumerarlas todas, pero que se podían estudiar las causas generales de donde provenían.

Mientras que la jerarquía eclesiástica defendía una ideología, la realidad y los fieles se encontraban en otro plano distinto. Al mismo tiempo, esta jerarquía acusaba de desunión a los periodistas católicos y ejercía una fuerte censura. Todo ello originó un fuerte rechazo popular, por lo que en los núcleos proletarios tuvo escaso éxito. Esto pudo venir provocado por la reducción de obras referentes a la cuestión social, por la utilización de un vocabulario mal elegido y violento, y por el efecto de la propaganda anticlerical y socialista. Una de las soluciones para tratar de paliar este problema fue el intento de incluir apartados referentes al estudio de los asuntos sociales y la entrega de hojas gratuitas. En este sentido, la atención a la familia y a los miembros de la misma, se configuraría como un elemento importante y que estaría muy presente.

\footnotetext{
${ }^{28}$ Uno de los últimos estudios al respecto lo encontramos en Crespo Pérez, A. 2000. Historia de la prensa periódica en la ciudad de Murcia. Murcia: Academia Alfonso X el Sabio.

${ }^{29}$ El cruzado, 6, 1 de junio de 1918, Murcia, Archivo Municipal de Murcia.
}

Hispania Sacra, LXVI

134, julio-diciembre 2014, 733-765, ISSN: 0018-215X, doi: 10.3989/hs.2014.067 


\section{LA FAMILIA Y EL MATRIMONIO A TRAVÉS DE LA PRENSA}

El modelo de familia defendido por la Iglesia católica puede definirse como único e invariable ${ }^{30}$ es decir, sólo se contempla un modelo familiar válido y de acorde con los preceptos marcados por la doctrina católica. Como no podía ser de otra forma, la familia estará presente en los diarios murcianos de comienzos del siglo xx, no sólo en artículos que describen las pautas familiares aprobadas por la Iglesia, sino también en aquellos que atacarán los modelos que no están de acuerdo con la ideología eclesiástica, los que recomiendan un determinado tipo de prácticas religiosas para llevar a cabo en el seno familiar o los que tratan de definir y organizar el hogar cristiano.

Para comenzar a caracterizar este modelo de familia cristiana esgrimido a través de la prensa, vamos a atender al artículo «Añoranzas» escrito por Ana Codorniú de Hernández Ros en el periódico Luz y amor. En dicho artículo, la autora lleva a cabo una descripción completa de lo que debe ser una verdadera familia que se orienta en la fe de Dios. Al mismo tiempo, la escritora aprovecha para mostrar su añoranza ante la paulatina desaparición de este modelo en el marco de la sociedad en la que vive. Así, se expone que el modelo ideal era aquel en el que las familias vivían unidas, reuniéndose a diario varias horas en el hogar y actuando de forma compenetrada entre los distintos miembros. La propia autora expone que «aquella vida casi patriarcal constituye un sueño dorado». ${ }^{31}$

A la vez, el artículo también se ocupa del resto de familiares y del comportamiento dentro de la casa, ya que por ejemplo alude a las reuniones familiares en las que los abuelos contaban sus recuerdos de juventud, los niños rezaban el rosario y donde se permanecía largo rato en familia; costumbre que estaba desapareciendo a favor de otras menos recomendables como la asistencia a los teatros. Este escrito da gran importancia al hecho de compartir en familia los rezos y las liturgias eclesiásticas como una forma de establecer en el seno de la familia la práctica de los cultos religiosos.

Otro de los rasgos que destacaba el artículo era el de la familia como transmisora de valores cristianos. Así, expone un modelo de imitación de las formas que debe pasar de los abuelos a los padres, y de éstos a los hijos, resaltando de esta forma la labor educativa de la familia:

\footnotetext{
${ }^{30}$ Los modelos familiares de la Restauración han sido estudiados en diversas obras: Muñoz López, P. 2001. Sangre, amor e interés. La familia en la España de la Restauración. Madrid: Marcial Pons; Roigé, X. 2011. «De la Restauración al franquismo. Modelos y prácticas familiares», en F. Chacón y J. Bestard (eds.), Familias. Historia de la sociedad española (siglos XIII-XXI): 667-741. Madrid: Cátedra.

${ }^{31}$ Luz y amor, 137, marzo de 1930, Murcia, Archivo Municipal de Murcia.
} 
«los hijos...respetaban a la par que amaban a sus padres, y como este respeto y este amor lo veían los nietos, lo sentían también por sus abuelos, y los abuelos de antes querían de verdad a su descendencia... alentaban a los padres a que educaran a sus hijos, no sólo en el temor a Dios sino que también resultaran obedientes».

De esta forma, queda claro que la familia cristiana tiene como una de sus misiones fundamentales educar a los hijos en la fe católica, transmitiendo los valores que la Iglesia considera como verdaderos. Por tanto, se concibe un modelo basado en el cumplimiento de la doctrina católica: una familia formada por un hombre y una mujer unidos en matrimonio con sus hijos, donde los abuelos deben ocupar también su papel y donde la jerarquía y el respeto a los superiores debe estar siempre presente. Al mismo tiempo, el temor a Dios tiene que primar en la educación de los hijos, pues al igual que los padres, se encuentra en un escalafón superior al de los vástagos.

La familia será considerada como uno de los pilares básicos de la sociedad y de la Iglesia, pues era la institución que nutría de nuevos fieles a la causa católica. Por tanto, la propaganda católica sentará rápidamente las bases de lo que considerará la «verdadera familia cristiana». El artículo «Los padres de familia», ${ }^{32}$ ofrece una descripción interesante a este respecto, ya que se encarga de ensalzar los valores y la naturaleza de la familia cristiana: de un lado, pone de manifiesto la enorme importancia que tiene la familia para la Iglesia, ya que relaciona la regeneración de la sociedad y de la Nación con el cambio dentro de la familia; y de otro lado, nos señala la visión pesimista que acompaña a los escritores católicos del momento, que explicaban la mala situación del país como consecuencia de la degradación moral de la sociedad, causa última de todos estos males.

No sólo se trataba de defender el modelo deseado y esperado para la familia, sino que se consideraba que la familia cristiana estaba en peligro. Por ello, la jerarquía eclesiástica se ocupará de denunciar y desprestigiar cualquier modelo familiar que no se encontrara dentro de sus límites y percepciones. Desde los periódicos se denunciaban los casos de las nuevas familias y de las nuevas costumbres que estaban surgiendo:

«Los cuidados del espíritu, la educación de los hijos ¡Ah!, todo eso ha pasado a segundo plano. Y esto no sólo en las familias que conviven con indiferencia o con ateísmo práctico, sino también en aquellas que presumen de católicas, en las que brilla por su ausencia el espíritu cristiano». ${ }^{33}$

Son muchos los ejemplos que concretan la pérdida de valores morales que se estaba produciendo dentro de la familia según la Iglesia. No sólo se consideraba

${ }^{32}$ La verdad, 9680, 26 de mayo de 1930, Murcia, Archivo Municipal de Murcia.

${ }^{33}$ La verdad, 9774, 28 de agosto de 1928, Murcia, Archivo Municipal de Murcia. 
que la auténtica familia estaba en peligro, sino que además se pensaba que estaba siendo atacada desde diferentes sectores como el de las corrientes laicas. En este sentido, no serán pocos los periodistas y sacerdotes que considerarán que uno de los motivos de la pérdida de valores familiares era la desobediencia de los hijos a los padres:

«la familia cristiana... está amenazada, como hemos dicho en otras ocasiones, por la falta de respeto a la autoridad de los padres, y quizá más, por falta del recto ejercicio de la autoridad por parte de éstos»..$^{34}$

La culpa no sólo era de los hijos, sino también de los padres, que no habían sabido educarlos en la obediencia a su autoridad natural. Esta idea es una de las premisas fundamentales que se marca desde la doctrina religiosa para la educación de los hijos, pues era muy importante que estuviera presente esa sumisión a los padres.

Otro de los elementos que la Iglesia católica defenderá desde sus medios de expresión será el de la realización de prácticas religiosas en el seno de la familia. Para ello, argumentará que éstas tenían dos buenos efectos: mantener unida a la familia y conseguir la gracia de Dios. En este sentido, la Iglesia también será tajante en cuanto a la puesta en práctica de las mismas: las familias que las llevan a cabo son las que cumplen con los preceptos religiosos y las que serán colmadas de una vida feliz; por el contrario, las familias que no realicen como es debido estas prácticas están destinadas al peor de los desenlaces.

La presencia de esta temática en la prensa será constante, recogiendo toda una serie de supuestos y de consejos a seguir por las familias. Curioso resulta el artículo «Las tres aves Marías y la familia» escrito por fray Andrés de Ocerín Jáuregui e inserto en la revista Espigas y Azucenas (publicación editada por los Padres Franciscanos y de gran repercusión para Murcia desde su origen en 1915). Este artículo expone la gran importancia que tiene la familia y los problemas por los que puede atravesar, siendo la solución para acabar con todos ellos el rezo en familia de las tres aves Marías. Al mismo tiempo, el autor, para demostrar la validez del método, exponía una serie de resultados:

«un esposo, que viviera algún tanto descuidado, declaró que con la práctica de las tres aves Marías tuvo un cambio radical en poco tiempo... una madre de familia arruinaba su casa, se pone a rezar todos los días y a los quince días declaró que iba mejor y que estaba contenta». .35

Este ejemplo deja claro la importancia que tiene para el religioso fomentar las prácticas religiosas en el seno de la familia, ya que ocasionan toda una serie

\footnotetext{
${ }^{34}$ La verdad, 6322, 28 de julio de 1920, Murcia, Archivo Municipal de Murcia.

${ }^{35}$ Espigas y azucenas, 112, 15 de agosto de 1919, Murcia, Archivo Municipal de Murcia.
} 
de buenos resultados y ayudan a que éstas sean transmitidas de generación en generación. De otro lado, y siguiendo con la argumentación anterior, en el artículo «El santo Rosario en la familia», ${ }^{36}$ se señala que el método más fiable para conocer el grado de santidad de una familia es el cumplimiento del rezo ordinario del santo Rosario. Nos dice el autor que todas aquellas familias que cumplan con este precepto gozarán de un buen sustento y una correcta educación.

Otra de las preocupaciones se matizará en la asistencia a los servicios públicos y ordinarios por parte de las familias. Ante esta cuestión, la prensa también alentará a acudir a la Eucaristía todos los domingos y en familia, con todos sus miembros, acción ésta que también traerá buenos resultados a las familias que la practiquen. Buen ejemplo de ello lo encontramos en el artículo «Los que no van a misa», ${ }^{37}$ donde el autor trata de ofrecer unos datos «científicos y médicos» de los malos resultados que obtienen en su vida aquellas personas que no acuden a la Eucaristía: «después de veinte años de atenta observación, ha escrito un célebre médico la siguiente estadística: de 342 familias desavenidas, conté 320 que nunca iban a Misa los domingos». De forma que la asistencia a los servicios religiosos se relacionaría directamente con el éxito y la fortuna en la vida.

Pero la atención por la familia se reflejará también en artículos de opinión destinados a la demanda de derechos y subsidios para las familias, más si se daba el caso de que fueran familias numerosas. Como muestra de lo que exponemos podemos citar el artículo, «De acción social. Los subsidios familiares. Las familias numerosas prestan servicios eminentes a la nación. ¿Qué se ha hecho en España? El ejemplo de Francia y Bélgica» de José Escámez. ${ }^{38}$ En dicho artículo se ensalza la labor de las familias numerosas, que nutren a la Nación de sus futuros trabajadores y militares. Al mismo tiempo, se señala que los subsidios familiares son tan necesarios como obligatorios, pues en cierta forma representan un premio a la gran labor que llevan a cabo estos cabezas de familias. Otro de los elementos que destaca el autor es que este tipo de ayudas sólo se han otorgado durante el periodo de gobierno de Primo de Rivera, pues «los socialistas son contrarios a la familia y a los subsidios familiares, poseen medios contrarios como el amor libre, la coeducación, el divorcio...». El autor fija dos posturas de forma clara: primero, la Iglesia es la única institución cuyo deseo es ayudar a la familia y a la Nación; y, segundo, el resto de ideologías se muestran contrarias al apoyo de las familias, argumentado esta idea a partir del ataque a los enemigos de la religión.

\footnotetext{
${ }^{36}$ Espigas y azucenas, 139, 15 de octubre de 1920, Murcia, Archivo Municipal de Murcia.

${ }^{37}$ Acción Social Antoniana, 40, enero de 1928, Murcia, Archivo Municipal de Murcia.

${ }^{38}$ Hoja del Asilo de la Purísima Concepción, 35, diciembre de 1933, Murcia, Archivo Municipal de Murcia.
}

Hispania Sacra, LXVI

134, julio-diciembre 2014, 733-765, ISSN: 0018-215X, doi: 10.3989/hs.2014.067 
El discurso anterior tenía dos claras intenciones: señalar la importancia de destinar ayudas a las familias y resaltar que la Iglesia católica era la principal institución que trataba de conseguirlas. Al margen de eso, otra de las pretensiones era argumentar cómo debían invertir su tiempo las familias de carácter más modesto, es decir, cuáles debían ser sus aficiones y entretenimientos, actividades que tenían que estar en función de su capacidad económica. Así, mediante el salario del padre y los subsidios obtenidos, la familia tenía que ajustarse a sus posibilidades económicas y no vivir por encima de éstas, pues no pertenecían a los sectores acomodados de la sociedad. Ante esta cuestión, el autor Pedro Sánchez Pérez escribe:

«el obrero y su familia deben tener comodidades y diversiones lícitas, pero las que corresponden a su clase modesta, querer igualarse a las clases más pudientes, es inmodesto, ridículo y ruinoso». .9

Con estos discursos, la Iglesia trata de justificar las diferencias sociales y económicas, argumentando que se debe aprender a vivir con ellas. En este sentido, vemos como la Iglesia no sólo se estaba ocupando de mantener el control espiritual de la familia, sino que pretendía llevar este control a terrenos más prácticos como el que representaban las actividades lúdicas y el entretenimiento. En otras palabras, se pretendía marcar y controlar los tiempos de las familias, adecuándolos a los tiempos religiosos.

Este intento de controlar los tiempos y ritmos de las familias también se hace patente en el caso de los días festivos, que serán señalados como las jornadas por excelencia para estar con la familia y compartir momentos de juegos y conversación. Es una forma más de marcar las pautas de la vida cotidiana de las gentes, dando consejos de lo mejor que se puede hacer en esos días y de qué cosas no deben realizarse por ser contrarias a la voluntad de Dios. A este respecto, el artículo «Guardad los días festivos» resulta clarificador:

«un día festivo debe ser el día de la familia. Al menos, en el día de fiesta reúnanse, entréguense a la dulce expansión mutua, cuéntense los sucesos de la semana... jueguen con los niños. Un día de familia puede alegrar a un obrero para toda la semana». ${ }^{40}$

Los buenos efectos de un día festivo en familia no podían ser más beneficiosos para quienes los practicaran.

Vemos claramente un modelo que se repite continuamente en la prensa católica de comienzos del siglo $\mathrm{xx}$ a la hora de tratar el tema de la familia cristiana. Así, el autor lleva a cabo en primer lugar un ensalzamiento de los valores

\footnotetext{
${ }^{39}$ Hoja del Asilo de la Purísima Concepción, 35, diciembre de 1933, Murcia, Archivo Municipal de Murcia.

${ }^{40}$ Luz y amor, 42, 29 de junio de 1918, Murcia, Archivo Municipal de Murcia.
} 
cristianos de la familia y de los buenos resultados que ofrece a las personas que los abrazan, sin olvidar nunca la labor educadora de la familia y la importancia de ésta para la Nación. En segundo lugar, realiza una denuncia de los peligros que acechan a la familia cristiana y de sus causantes, dando una visión fatalista de la situación y poco esperanzadora. Por último, la solución que ofrece la Iglesia para recuperar el buen rumbo de la familia es llevar a cabo las prácticas religiosas en familia, ya sea en el marco del hogar o bien acudiendo los domingos al templo.

El reflejo de la buena familia cristiana debía hacerse realidad en el ámbito compartido por todos sus miembros, el hogar, símbolo por excelencia del buen hacer de las personas cristianas y caballo de batalla de la prensa católica. Vamos ahora a analizar cómo debía de ser un hogar que reflejara el estilo de vida propuesto por la Iglesia católica. Baste esta descripción para entender lo que se pretendía conseguir:

«Haz vida de familia y piensa que en ninguna parte estarás mejor que en tu casa, en el hogar bien formado, y vivificado todos los días a fuerza de amor y de sacrificios mutuos». ${ }^{41}$

Nuevamente en este caso, los autores de ideología católica van a diferenciar los dos modelos posibles de hogar, pero mostrando siempre que sólo uno de ellos es el válido y aceptado por parte de la doctrina eclesiástica. Como en ocasiones anteriores, se definirán dos tipos de hogares, el cristiano y el pagano, antítesis el uno del otro y enemigos por todo lo que representan:

«En el hogar cristiano se quiere dejar a salvo la dignidad, los deberes, las obligaciones, los deseos lícitos. En el pagano se antepone el placer a las obligaciones, con la falta de altruismo, con el desenfreno de los apetitos». ${ }^{42}$

En esta clasificación se sigue utilizando el mismo patrón que ya se había usado para los elementos anteriores, sólo el modelo inspirado en la religión es el válido y el aceptado por la Iglesia, el resto de alternativas están equivocadas y son las que provocan las desgracias de los hombres.

La naturaleza de cada uno de estos hogares vendrá determinada por el comportamiento de la familia que viva en ellos. Así, para el hogar cristiano se busca vivir bajo dos preceptos claves: la unidad y la indisolubilidad. Bajo estos elementos, los hijos se convertirán en una bendición para los padres y serán la auténtica riqueza del hogar. En este sentido se considera que el matrimonio ha sido acertado y ha sabido constituir un auténtico hogar cristiano. En el vértice opuesto encontramos el hogar pagano, que abandona la religión y a Dios, por lo

${ }^{41}$ Espigas y azucenas, 344, 2 de diciembre de 1928, Murcia, Archivo Municipal de Murcia.

${ }^{42}$ La verdad, 10503, 9 de diciembre de 1930, Murcia, Archivo Municipal de Murcia. 
que se van a producir los efectos opuestos al hogar cristiano. De esta forma, el matrimonio vivirá separado y no se apoyarán los esposos, los hijos no serán obedientes y no se mostrarán agradecidos con sus progenitores, no será el modelo de familia deseable para ninguno de sus miembros. La Iglesia es tajante en este aspecto, el hogar que no sea cristiano está abocado a la disolución. Asimismo, resulta interesante la equiparación que realizan estos escritores, pues según ellos, el final de la familia y los males que la persiguen se deben sobre todo a la existencia de estos hogares paganos. Por ello, podemos decir que se pretende convencer a las gentes de que el hogar cristiano es la única solución posible para el mantenimiento de la familia, de ahí la importancia que darán a este tipo de temas en la prensa.

Las alabanzas que se llevarán a cabo del hogar cristiano van a ser numerosas y ricas en matices, ya que como decíamos anteriormente, al considerar el hogar como un apéndice de la familia, la Iglesia se esforzará en tratar de transmitir el modelo defendido por sus catecismos. Muestra de este panorama nos lo ofrece el artículo «Vida cristiana», que lleva a cabo un ensalzamiento del hogar cristiano, de sus valores, frutos y buenos resultados:

«¿Has pensado lector en la belleza del hogar cristiano? ¿Qué es un hogar cristiano? Un oasis en el desierto inmenso de la vida, un ameno jardín deleitoso semejante al paraíso. Morada de la concordia, de la paz y del amor puro». ${ }^{43}$

El hogar religioso sería sinónimo, por tanto, de las mayores bondades del mundo y de la familia. Como vemos, se trata de una retórica grandilocuente que tiene como objetivo sobrevalorar los resultados positivos que ocasiona el hogar que se adapta a la doctrina eclesiástica. Al tiempo que no deja de ser una forma más de tratar de controlar a través de la prensa cómo debía ser la vida de las familias en los hogares, ya que como se ha señalado anteriormente, el periódico había comenzado a formar parte de las estrategias de la Iglesia para recuperar su preponderancia en el marco de la sociedad.

El artículo anterior también marca en cierta medida cuáles debían ser los papeles de cada uno de los miembros de la familia que formaban parte de dicho hogar, así, para el hombre se decía que debía mostrarse redentor y paciente: «la amabilidad del esposo, la afabilidad del padre». El caso de la mujer era bien distinto, pues no podía equipararse a la figura del marido: «La prudencia y sobrio hablar de la madre. La solicitud incesante de la madre» eran los rasgos que debía cumplir la mujer. Para los hijos se repiten los cánones anteriormente mencionados de obediencia y sumisión a los padres, que en este caso se hacían extensibles a los sirvientes que se encontraran en la casa: «La obediencia reverente de los hijos. La fidelidad de los sirvientes». Termina el autor señalando que «El hogar

\footnotetext{
${ }^{43}$ Espigas y azucenas, 302, 1 de marzo de 1927, Murcia, Archivo Municipal de Murcia.
} 
cristiano tiene mucho del paraíso terrenal», es decir, la mejor forma de vivir en la tierra es a través de la asimilación de los principios cristianos como directores del hogar. La vida en un hogar cristiano sería lo más parecido a la posterior vida del creyente en el Cielo, que será uno de los premios otorgados junto a la salvación y la vida eterna.

De esta forma, la preocupación por mantener alejados lo que la Iglesia consideraba como vicios y malos hábitos dentro del hogar estará presente en la prensa diaria de la época, repitiendo siempre esa fórmula que los escritores católicos parecían tener bien aprendida: elogio de las virtudes del hogar cristiano, demonización del hogar que no siguiera este modelo, y descripción del papel y de las virtudes de cada uno de los miembros de la familia dentro del hogar.

El artículo «El niño y el hogar» representa un claro ejemplo de este esquema. ${ }^{44}$ Comienza el autor llevando a cabo un ensalzamiento de los valores de la familia y del hogar cristiano, «la felicidad de la familia va a ser privilegio asequible a los hogares que conserven en su ámbito el aroma de la religión», es decir, nuevamente se relaciona el éxito y la buena marcha de la familia con la presencia en el seno de la misma de la religión y de sus prácticas. Por contraposición, todo lo que representa el hogar cristiano es contrario a lo que manifiesta el hogar pagano, por lo que sólo se debe aceptar este modelo, mientras que el otro debe ser erradicado y combatido:

«La indiferencia y la apostasía son palabras que aquí envuelven a más de un desaire y un reniego injurioso a Dios, un ultraje manifiesto al nombre y al historial de gloria rubricados por la probidad intachable de muchas conciencias».

$\mathrm{El}$ ataque a lo que la doctrina eclesiástica consideraba como desviaciones del hogar cristiano tendrá gran cabida en la prensa. Al tiempo, otro tema que se tendrá en cuenta será la denuncia de la situación que según estos autores se estaba viviendo, que tenía como resultado la destrucción del modelo cristiano de familia y del hogar. Aquí tenemos un ejemplo de esto que estamos mencionando, donde se vuelven a enumerar todos los vicios que lleva consigo la vida en un hogar pagano y alejado de la doctrina de Dios:

«Hoy por desgracia, muchas casas de familia parecen fondas o lugares de asistencia... El padre por una parte; la madre por otra; las hijas flirteando locamente a todo hijo de vecino; y los muchachos campando por donde se les antoja». ${ }^{45}$

Otra de las ideas interesantes que se desprenden de los textos anteriores es la de la equiparación del hogar con un santuario. Así, el propio autor del artículo de Acción Social Antoniana señala «el hogar-santuario es una idea que reverbera

${ }^{44}$ Acción Social Antoniana, 45, junio de 1928, Murcia, Archivo Municipal de Murcia.

${ }^{45}$ Espigas y azucenas, 344, 2 de diciembre de 1928, Murcia, Archivo Municipal de Murcia.

Hispania Sacra, LXVI

134, julio-diciembre 2014, 733-765, ISSN: 0018-215X, doi: 10.3989/hs.2014.067 
apacible en el medio ambiente familiar»; es decir, el hogar debe ser un apéndice más del templo, un lugar dedicado también al culto y a la oración, pero en familia y de forma conjunta. Ésta es una idea muy reveladora, pues muestra como la Iglesia pretende sentar las bases de la convivencia dentro de los espacios más privados, de modo que no sólo trataría de reglar la convivencia en el templo y en la calle, ámbitos de carácter más público, sino que el hogar, como ámbito privado, también quiere ser controlado por la Iglesia. Para ello, que mejor manera de dirigirlo que mediante la conversión en una especie de extensión del templo.

Las prácticas religiosas en familia no eran la única forma de equipar la casa con la iglesia, esta dimensión también debía ser visible exteriormente para todos. Así, la manera de que el hogar se pareciera más a la iglesia era decorarla de forma similar, de modo que la religión estuviera presente. Se pretendía que dentro de este «santuario de la familia» se encontraran elementos que recordaran la fe y el dogma: «el crucifijo, la placa del Corazón de Jesús y de la Dulcísimo Madre de Dios, el cuadro inspirado en la riquísima hagiografía cristiana, dominante en puesto de preferencia». Para la elección de los ornatos religiosos que decoran cada uno de estos hogares, también entrarían en juego las distintas devociones y creencias de cada una de las familias, marcando sus preferencias y gustos. Al mismo tiempo, la decoración, aunque debía ser religiosa, no podía mostrase ostentosa, sino basarse en la humildad y en la moderación:

«hábito de sencillez y moderación campean dondequiera: en la casa, en los vestidos, en los muebles, en los cuadros, en la mesa. El boato engañador de las fiestas mundanas se quiebra lejos de aquí». ${ }^{46}$

La austeridad, por tanto, era muy valorada en los hogares cristianos. Esta cualidad también se tenía que reflejar en la huída de las fiestas mundanas, pues las familias sólo debían participar de los festejos religiosos, que eran los auténticamente válidos e importantes. Una muestra de lo anterior también nos la ofrece el artículo «Casa cristiana, reino de paz», donde se expresa:

«en el ajuar de vuestra casa no han de faltar imágenes devotas, no sólo en las habitaciones interiores, sino en las que dan a la calle, en la sala principal, en el corredor... Bueno sería también que se pusiese en la entrada una placa del Sagrado Corazón o de la Virgen». ${ }^{47}$

De este fragmento se deslizan dos elementos interesantes. Nuevamente se lleva a cabo una defensa de la necesidad de que la religión esté presente en el hogar a través de la decoración y el ornato. De otro lado, el autor señala como la familia no sólo debe ser cristiana, sino también parecerlo. Por tanto, no sólo hay que decorar el interior de la casa, sino también el exterior, lo que ve el resto de

\footnotetext{
${ }^{46}$ Acción Social Antoniana, 45, junio de 1928, Murcia, Archivo Municipal de Murcia.

${ }^{47}$ Espigas y azucenas, 344, 2 de diciembre de 1928, Murcia, Archivo Municipal de Murcia.
} 
la comunidad de creyentes. Así, toda persona que pase cerca podrá comprobar cuáles son las devociones de la familia y entenderá que la religión forma parte de ese hogar. En este sentido, vemos una equiparación de los espacios públicos y privados, mezclando elementos de unos con los otros, a fin de reforzar el argumento que se trata de defender.

Vamos a prestar también atención a otro tema referente a la buena marcha del hogar, aspecto que comenzará a cobrar importancia poco a poco, pero que pasados unos años se encontrará muy presente en los escritos de la prensa católica del momento. Este tema no podía ser otro que el de las fiestas y el de la vida fuera del hogar. Si antes decíamos que el hogar tenía que ser como una extensión del templo, ¿qué mayor enemigo podía tener el hogar que los entretenimientos y espectáculos mundanos? Así, todos aquellos elementos que supusieran la salida del hogar y el relajamiento con respecto de la familia, estarían mal vistos y serían atacados por la doctrina de la época. Los espectáculos, cafés, cines o teatros van a ser enemigos acérrimos del hogar y de la familia, pues confundían a las gentes y les hacían olvidar sus verdaderos deberes para con Dios y su familia.

Las fiestas también serán el otro caballo de batalla de la Iglesia, no sólo las exteriores, sino también las que se celebraban en el interior de los hogares. Éstas eran totalmente reprobadas por la Iglesia, ya que sólo eran acicate de nuevos vicios y perversiones para las familias. Se pretendía mantener la santidad de los hogares cristianos, y para ello, había que alejarlos de los vicios y de los entretenimientos del mundo. La lucha de la Iglesia contra este tipo de entretenimientos no era nueva, lo que sí destaca es la fuerte vinculación que llevará a cabo entre estos espectáculos y la ruina que provocaba en los hogares. Establece así una relación causa-efecto directa entre ambos elementos, que sólo podía resultar perjudicial para el hogar cristiano.

El artículo «La felicidad de los hogares» da buena muestra de ello. La calle, y todo lo que de ella se desprende, se configurará como uno de los grandes enemigos de los hogares cristianos. Así, la solución a este peligro era llevar una rutina lo más ordenada posible y apartada del mundo exterior. La vida debía configurarse en el seno de la Iglesia, haciéndola extensible a la familia y al hogar:

«hay personas que todo lo echan a la calle. Calle en esta ocasión significa fiestas, diversiones, teatros, parrandas con amigos y, en la mujer sobre todo, vestidos a cada hora, a cada momento». ${ }^{48}$

Vamos a ocuparnos ahora de los diferentes roles que debían jugar cada uno de los esposos dentro del matrimonio. Así, tenemos que destacar que serán

${ }^{48}$ Espigas y azucenas, 324, 1 de febrero de 1928, Murcia, Archivo Municipal de Murcia.

Hispania Sacra, LXVI

134, julio-diciembre 2014, 733-765, ISSN: 0018-215X, doi: 10.3989/hs.2014.067 
más numerosos los escritos dedicados a explicar el papel que debe esgrimir la esposa con respecto a los artículos que recogen el rol encomendado al esposo. De esta forma, se considerará más importante argumentar y controlar la labor de la mujer, siendo ésta una de las primeras características que encontramos. En este discurso se vinculará a la mujer con el ámbito privado (basado en el cuidado del hogar, la educación de los hijos y la atención de su esposo), ${ }^{49}$ mientras que al hombre se le relacionará con el ámbito público, es decir, el mundo fuera del hogar y con el trabajo.

Podemos destacar el artículo «El hombre y la mujer», donde el autor ofrece una serie de diferenciaciones muy significativas entre el papel adjudicado a cada uno de los géneros. Si lo analizáramos cualitativamente, el hombre saldría beneficiado a todas luces, pues la mayor parte de atributos y virtudes caen de su lado, mientras que la mujer, a pesar de presentar también una serie de elementos positivos, encarna otros elementos menos deseables como la debilidad o la necesidad de protección. De esta forma, el escritor sitúa al hombre por encima de la mujer, utilizando para ello sendas metáforas: «el hombre es la más elevada de las criaturas. La mujer es el más sublime de los ideales». ${ }^{50}$

Al mismo tiempo, también se muestra la superioridad intelectual del hombre, entendida ésta como un elemento que se encuentra en la propia naturaleza del género humano; por ello, la mujer debe someterse al ser superior que representa el hombre: «el hombre es el cerebro; la mujer el corazón. El hombre es el genio. La mujer es el ángel». Una vez más se diferencian las cualidades de un género y del otro: mientras que el hombre tiene una serie de virtudes que se vinculan más con la inteligencia y el mundo público, la mujer posee unas cualidades que se reflejan más en el aspecto espiritual de la vida y en el ámbito privado. Se trata de esta forma de justificar el papel de cada uno de los esposos como si de un designio divino se tratará, como si estuviera en la esencia natural de hombres y mujeres.

La debilidad que se le asigna a la mujer será otra de las distinciones que encontramos. De esta forma, serán necesarios los cuidados del hombre y su protección, por lo que se da una imagen en la que las mujeres debían apoyarse y ser vigiladas por el sexo masculino.$^{51}$ En este aspecto, el artículo también es claro,

\footnotetext{
${ }^{49}$ Estudiado en Cantero Rosales, M. 2007. «De perfecta casada a ángel del hogar o la construcción del arquetipo femenino en el siglo XX». Revista electrónica de estudios filológicos 14; Arce Pinedo, R. 2008. Dios, Patria y hogar: la construcción social de la mujer española por el catolicismo y las derechas en el primer tercio del siglo XX. Cantabria: Universidad de Cantabria.

${ }^{50}$ Espigas y azucenas, 263, 1 de diciembre de 1925, Murcia, Archivo Municipal de Murcia.

${ }^{51}$ Se tratará a la mujer como un ser débil al que se debe proteger, por ello algunos autores han señalado que a través del Código Civil de 1889 se potenció esa concepción de la mujer como un ser diferente, débil y necesitado de protección: Irigoyen López, A. 2011. «Estado, Iglesia y familia: la complejidad de los cambios legislativos y socioculturales», en F. Chacón y J. Bestard (eds.), Familias. Historia de la sociedad española (siglos XIII-XXI): 599-600. Madrid: Cátedra.
} 
«El hombre es fuerte por la razón; la mujer es invencible por las lágrimas. La razón convence; las lágrimas conmueven». Mientras que los hombres cuentan con el raciocinio y la fuerza, las mujeres deben contentarse con sus lágrimas y su capacidad para conmover al hombre. Así, se puede señalar que desde la prensa se promovía una imagen de la mujer que no podía valerse por sí misma, que necesitaba del hombre y que hacía gala de unas características que se basaban en su flaqueza.

La preocupación por el rol desempeñado por la esposa será constante, por lo que encontramos numerosos ejemplos al respecto. En el artículo «Donde las dan las toman» se llevan a cabo una serie de comparaciones curiosas de cómo debe ser la mujer y cómo debe comportarse con su marido:

«Según un periódico inglés, la esposa perfecta debe ser como un buen reloj municipal, por su puntualidad y regularidad; como el caracol, por la prudencia y el hábito de estar siempre en su casa; como el eco, que contesta siempre que se le pregunta». ${ }^{52}$

Siguiendo con estas equiparaciones, el artículo utiliza también estas curiosas metáforas para señalar lo que no debe representar una esposa:

«Pero no debe, como el reloj, hablar tan alto que todo el pueblo la oiga; ni llevar como el caracol, toda su fortuna a la espalda; ni como el eco, obstinarse en decir siempre la última palabra».

O lo que es lo mismo, la esposa debe ser prudente, ahorrativa y obediente, características que van a estar muy presentes en el discurso defendido por la prensa católica de la época para confeccionar el modelo de mujer que deseaba la Iglesia.

Otros artículos, utilizando un lenguaje más pomposo y adornado, van a señalar elementos similares a los ya expuestos con anterioridad. Hay que destacar en este caso las consecuencias que sufre el hogar y el matrimonio en el que la esposa no adopta su papel correspondiente. Como en otras ocasiones, la buena marcha de la familia y del matrimonio dependía de la aceptación de las normas que marcaba la Iglesia y de su cumplimiento por parte de los esposos, de lo contrario, los resultados no podían ser peores:

«el espíritu de abandono, la falta de limpieza que preside en aquellos lugares de familia, de matrimonio, donde la mujer ignora los rudimentos de la vida».53

Por otro parte, en ese diseño del papel de la esposa, también se dedicaban grandilocuentes elogios a las mujeres que cumplían estos preceptos. Se trataba de animar al sector femenino para que se sometiera a los designios de la doctrina

${ }^{52}$ Espigas y azucenas, 236, 15 de octubre de 1924, Murcia, Archivo Municipal de Murcia.

${ }^{53}$ Espigas y azucenas, 358, 1 de julio de 1929, Murcia, Archivo Municipal de Murcia.

Hispania Sacra, LXVI

134, julio-diciembre 2014, 733-765, ISSN: 0018-215X, doi: 10.3989/hs.2014.067 
eclesiástica. Así, los artículos que ensalzarán la figura de la buena esposa van a ser numerosos, al tiempo que denunciarán los peligros que amenazaban a las mujeres que hacían caso omiso de sus recomendaciones. La revista Espigas y azucenas en su artículo «Lo que vale una esposa...», ${ }^{54}$ recoge algunos de los elogios que se llevan a cabo hacia estas mujeres:

«Una esposa, una buena esposa es un tesoro invaluable. No hay dinero en el mundo con que poder pagar, materialmente, el amoroso compañerismo de la mujer».

Sin embargo, este artículo no se queda sólo en el elogio fácil, sino que va más allá e introduce una idea novedosa para la época y para la institución de la que estamos hablando: se trata del reconocimiento del trabajo de la mujer en la casa. Además, añade que hay que entenderlo como un elemento que se debe valorar y equiparar con el trabajo que desempeñan los hombres fuera del hogar.

Para acabar con la caracterización del papel y figura de la esposa dentro del matrimonio cristiano, vamos a señalar un artículo que nos sirve a modo de resumen y conclusión de las ideas que apuntábamos con anterioridad. Ya hemos visto la separación de funciones y roles que se llevan a cabo entre los esposos, la condena que se hace de aquellos matrimonios que no siguen con las pautas establecidas y el continuo elogio que se llevará a cabo de las esposas que cumplan celosamente con los cometidos señalados por la doctrina. De esta forma, en «Decálogo de la esposa», se recogen todos los elementos con los que debe de cumplir la «buena esposa», características que ya hemos apuntado con anterioridad, pero que el artículo señala de forma ordenada y muy concisa, por lo que se ha considerado que su reproducción puede resultar interesante:

«1. Amarás a tu hogar sobre todas las cosas y a tu esposo como a ti misma; 2 . No le ocultes ninguno de tus pensamientos; 3 . En los conflictos de la vida doméstica, defiende y disculpa a quien tenga razón, pero sin dársela; 4. Vigila sin espiar, 5. Haz por compartir las grandes penas de tu esposo; 6 . Destruye los celos en cuanto aparezcan en tu corazón; 7. Quiere a tus padres políticos como una verdadera hija; 8 . No permitas que se desconozca la autoridad conyugal en tu hogar; 9 . No olvides que para ser feliz has de regir la casa con energía y prudencia...; 10. Si tienes hijos, ámalos por igual».55

Esta enumeración habla por sí sola de lo que se espera de la esposa, a la vez que señala de forma exacta las normas y deberes por las que debe regirse la mujer. Destacando nuevamente el papel que tiene la esposa con respecto a su marido, al que debe de ayudar y de apoyar, tratando de entenderlo y animándolo a seguir con sus cometidos. Amando siempre a los hijos, pero enseñándoles también que el hogar debe gobernarse en todo momento por la autoridad de los padres. También está presente, una vez más, la prudencia y la aceptación de las

\footnotetext{
${ }^{54}$ Espigas y azucenas, 361, 15 de agosto de 1929, Murcia, Archivo Municipal de Murcia.

${ }^{55}$ Acción Social Antoniana, 69, junio de 1930, Murcia, Archivo Municipal de Murcia.
} 
contrariedades de la vida, que deben ser asumidas por la esposa conforme vayan llegando. En este sentido, la resignación de la esposa debe ser total en todos los aspectos de su matrimonio, no sólo con los problemas de la vida, sino también con su marido, ya que la esposa debe ser paciente y conseguir solucionar los problemas que éste tenga; los problemas del hombre son los importantes, los de la mujer no lo son tanto. Por ello, prudencia, resignación, obediencia y respeto son palabras que la esposa debe conocer muy bien a la hora de actuar con su marido en particular y con su familia en general.

\section{CONCLUSIONES}

Hemos comprobado cómo la prensa fue uno de los medios utilizados por la Iglesia para hacer llegar su doctrina y modelos al pueblo. No obstante, aunque medio de difusión de sus ideas, debemos señalar que su eficacia y resultados vendrían marcados por el estigma que representó la tardía aceptación de este medio como un canal de difusión ideológica entre la masa social, otorgando unos resultados que podemos valorar de negativos para los intereses de la Iglesia católica. Mientras otros sectores ideológicos ya habían organizado la maquinaria informativa para hacer llegar a la sociedad sus inquietudes, los escritores católicos partían desde una posición de desventaja. En muchas ocasiones, esta desventaja a la que aludimos, se unió a la escasez de medios y a la falta de costumbre entre los propios escritores católicos, dando como resultado una serie de efectos negativos en los inicios, como demuestra la tardía creación de un periódico de tirada nacional que lograra asentarse entre sus sectores. ${ }^{56}$

Muestra también de estos problemas iniciales, la encontramos en la serie de campañas realizadas desde la propagandística católica: desde la creación y popularización de los términos «buena prensa» y «mala prensa» hasta la institución de festividades concretas para ensalzar la primera de ellas (Día de la Buena Prensa). No faltarán tampoco las recogidas de fondos entre los fieles y las arengas en artículos de periódicos y revistas en los que se vinculaba el pecado con la mala prensa y la salvación del alma con la buena. Por todo ello, el mundo eclesiástico tratará, tras aceptar la necesidad de contar con la prensa como uno de sus medios de difusión, de crear un clima de aceptación y de propaganda de sus escritos entre las gentes. Era evidente que la Iglesia católica debía recuperar las posiciones perdidas lo antes posible dentro del marco social.

\footnotetext{
${ }^{56}$ A pesar de esta tardía incorporación y los resultados negativos que exponemos, encontramos muestras de la acción católica en los medios periodísticos a lo largo del siglo XIX, sobre todo en torno al papel de la mujer, estudiado en: Perinat, A. y Marrades, M ${ }^{\mathrm{a}}$ I. 1980. Mujer, prensa y sociedad en España, 1800-1939. Madrid: Centro de Investigaciones Sociológicas.
}

Hispania Sacra, LXVI

134, julio-diciembre 2014, 733-765, ISSN: 0018-215X, doi: 10.3989/hs.2014.067 
Uno de los medios que la Iglesia articuló para difundir su sociedad ideal era la familia. Por esta razón, ocupará un lugar privilegiado dentro de las temáticas esgrimidas en los artículos periodísticos, por lo que será tratada de forma abundante y recurrente en las distintas publicaciones ofrecidas a los lectores. En este sentido, tras el análisis efectuado anteriormente, parece clara la comparación que se establece entre la familia y la Iglesia, como si de elementos semejantes se trataran. De forma que la familia debe aspirar a ser una imitación de la comunidad religiosa, a cada uno de sus miembros le queda reservada una misión, y a la vez, todos sus miembros deben obediencia a Dios y a la Iglesia, que representa a éste en la tierra.

Por todo ello, los escritores de la prensa católica no escatimarán esfuerzos en establecer el modelo católico para la familia y en denunciar las desviaciones del mismo que encuentran en la sociedad. En este punto, la línea de pensamiento recogida será bastante clara, la familia que sigue las doctrinas cristianas es la familia destinada a la salvación, el resto de opciones sólo pueden estar reservadas al pecado y a la condena. Para reforzar toda esta argumentación, se relacionará el bienestar de la familia con el bienestar de la sociedad en general y de la Nación, por lo que se dejaba entrever que los principios cristianos no sólo se preocupaban de la salvación de las almas sino también de la buena marcha del país.

La familia al igual que la Iglesia, debía reunirse en su templo por excelencia, el hogar. De modo que la comparación a la que aludíamos anteriormente seguía concretándose de esta forma: el templo de la familia sería el hogar, reflejo de la buena marcha de la familia y espacio físico donde sólo podía desarrollarse. Al igual que en el caso anterior, serán numerosos los artículos que tratarán de organizar el hogar y exponer qué elementos debían de formar parte de él. Serán dos las preocupaciones que marcarán este tipo de escritos. De un lado se atenderá a la decoración de los hogares con motivos religiosos, como si de una imitación del templo se tratará (se debía mostrar también hacia el exterior que se trataba de un hogar católico); y de otro lado, siguiendo con esa equiparación con el templo, se hará hincapié en el rezo en familia, muy importante para estos escritores. Dentro de esta práctica, se debía contar con toda la familia: el padre actuando como director de la escena y los hijos aprendiendo los valores religiosos.

No sólo se establece el modelo de familia y el ámbito ideal donde debía desarrollarse, sino que como hemos visto, se trataba de mantener el control de la familia a través del sometimiento de la mujer. Todo ello se explica a través de la tradicional subordinación que la mujer había padecido de manos del hombre y de su mayor relación con el mundo de la religión. De forma que muchos de estos artículos se centrarán en las funciones y en el rol de la esposa, destinándola al mundo del hogar y desterrándola del ámbito público, mostrándole que su principal misión era la de ser madre (y por extensión dedicarse a la educación de sus hijos) y obedecer a su marido, al que debía cuidar y atender. Evidentemente, se aconsejará la resignación y la comprensión, marcando además toda una serie de 
pautas de comportamiento de la esposa hacia el marido; tendentes todas ellas a conseguir la felicidad del varón frente a la indiferencia mostrada hacia la mujer. El control de la familia pasaba por seguir manteniendo la subordinación de la mujer, y los medios católicos darían buena cuenta de ello.

En última instancia, todo lo anterior debe hacernos reflexionar sobre la etapa a la que nos estamos refiriendo, periodo marcado por una serie de cambios importantes en el marco general de la sociedad. Términos como laicismo, secularización, feminismo, socialismo o comunismo comenzarían a sonar con más fuerza, y la Iglesia católica empezaba a temer que su incuestionada primacía social sufriera ataques que acabaran con la misma. De forma que debemos ver en la defensa de la familia a través de la prensa una muestra más de la combatividad y de la reacción de los sectores eclesiásticos frente a las nuevas corrientes de pensamiento que estaban irrumpiendo en el seno de la sociedad. El mensaje seguía siendo el mismo, había cambiado el enemigo y el medio de expresión, el púlpito y el confesionario ya no bastaban para seguir manteniendo el control de una sociedad que se enfrentaba a nuevos cambios de forma continuada. La familia será uno de los muchos frentes abiertos, frentes a través de los cuáles se pretendía seguir manteniendo el control y la influencia eclesiástica en la sociedad. No sólo debía luchar contra el anteriormente anatemizado poder civil, sino que nuevas fuerzas se oponían a la Iglesia, nuevas formas de familia y nuevas formas de entender las relaciones entre las parejas que ponían en peligro la posición principal de la Iglesia.

Como hemos visto, el estudio de la familia (sus modelos, sus valores, sus necesidades) a través de la prensa nos da una muestra más de la conflictividad social que marcó los inicios del siglo xx español. Conflictividad que estaría muy presente al menos durante el primer tercio del siglo y que tuvo importantes repercusiones. De forma que no se trata sólo de estudiar un determinado modelo teórico propuesto por una institución como la Iglesia, sino que se trata de dar un paso más y comprender cuál era la realidad de la sociedad, qué cambios y permanencias se dieron, cómo reaccionaron las gentes que vivieron dichas transformaciones y cómo fueron estos cambios lentos pero a la vez decisivos. Por todo ello, la familia, la Iglesia y la prensa forman un triángulo cuyo estudio puede depararnos en el fututo buenos resultados y puede, en definitiva, ofrecernos nuevas perspectivas de análisis y de comprensión de la historia.

\section{BIBLIOGRAFÍA}

Alonso Navarro, S. 1987. Prensa murciana del siglo xIx: El Semanario Murciano, El Diario de Murcia, Heraldo de Murcia. Murcia: Asociación de la Prensa de Murcia.

Andrés-Gallego, J. 1975. La política religiosa en España, 1889-1913. Madrid: Editora Nacional. 
Andrés-Gallego J. y Pazos, A. M. 1999. La Iglesia en la España contemporánea, 1800-1936. Madrid: Encuentro.

Arce Pinedo, R. 2008. Dios, Patria y hogar: la construcción social de la mujer española por el catolicismo y las derechas en el primer tercio del siglo XX. Cantabria: Universidad de Cantabria.

Arroyo, M. 2000. «La prensa católica: La Verdad de Murcia (1903-1988)». Hispania Sacra 106: 541-554.

Benavides, D. 1978. Democracia y cristianismo en la España de la Restauración, 1875-1931. Madrid: Editora Nacional.

Blasco Herranz, I. 2002. «Tenemos las armas de nuestra fe y de nuestro amor y patriotismo; pero nos falta algo. La Acción Católica de la Mujer y la participación política en la España del primer tercio del siglo xx». Historia Social 44: 3-20.

Botrel, J.-F. y Desvois, J.-M. 1991. «Las condiciones de la producción cultural», en S. Salaün y C. Serrano (eds.), 1900 en España: 33-58. Madrid: Espasa Calpe.

Callahan, W. J. 2003. La Iglesia católica en España (1875-2002). Barcelona: Crítica.

Cantero Rosales, M. 2007. «De perfecta casada a ángel del hogar o la construcción del arquetipo femenino en el siglo xx». Revista electrónica de estudios filológicos 14.

Castillo, J. J. y Vilar, P. 1977. El sindicalismo amarillo en España: aportación al estudio del catolicismo social español (1912-1923). Madrid: Cuadernos para el diálogo.

Crespo Pérez, A. 1986. La prensa periódica en la ciudad de Murcia (1706-1986). Murcia: Caja de Ahorros de Alicante y Murcia.

De La Cueva J. y Montero F. (Eds.) 2007. La secularización conflictiva. España (1898-1931). Madrid: Biblioteca Nueva.

De Lara Fernández, F. y Fresneda Collado, R. 1996. Catálogo de publicaciones de la Región de Murcia (1876-1939). Murcia: Fundación Instituto de la Comunicación de Murcia.

De Los Reyes, A. 1996. «La prensa murciana en el siglo XIX: una aproximación». Anales de Historia Contemporánea 12: 343-370.

Espadas Burgos, M. 1983. «La Iglesia española y la primera guerra mundial», en M. Espadas Burgos (ed.), Iglesia, sociedad y política en la España contemporánea: 131158. El Escorial: Ediciones Escurialenses.

Espina, A. 1960. El cuarto poder. Cien años de periodismo español. Madrid: Aguilar.

Fuentes, J. y Fernández Sebastián, J. 1998. Historia del periodismo español: prensa, política y opinión pública en la España contemporánea. Madrid: Síntesis.

Gay Armenteros, J. C. 2005. «La lucha por la opinión pública en Granada hasta el franquismo», en J.-L. Ruiz Sánchez (Coord.), Catolicismo y comunicación en la historia contemporánea: 15-30. Sevilla: Universidad de Sevilla. 
Gómez Aparicio, P. 1967. Historia del periodismo español. Madrid: Editora Nacional.

González Castaño J. 1996. La prensa local en la Región de Murcia (1706-1939). Murcia: Universidad de Murcia.

Hibbs-Lissorgues, S. 1995. Iglesia, prensa y sociedad en España (1868-1904). Alicante: Instituto de Cultura Juan Gil-Albert.

Irigoyen López, A. 2011. «Estado, Iglesia y familia: la complejidad de los cambios legislativos y socioculturales», en F. Chacón y J. Bestard (eds.), Familias. Historia de la sociedad española (siglos XIII-XXI): 515-600. Madrid: Cátedra.

La Parra López, E. y Suárez Cortina, M. (Eds.) 1998. El anticlericalismo español contemporáneo. Madrid: Biblioteca Nueva.

Laboa, J. M. 1994. La Iglesia del siglo XIX. Entre la Restauración y la Revolución. Madrid: Publicaciones de la Universidad Pontificia Comillas.

Lannon, F. 1990. Privilegio, persecución y profecía. La Iglesia católica en España, 1875-1975. Madrid: Alianza.

Longares Alonso, J. 1978. «Los canales de difusión de ideas en los comienzos del liberalismo español», en M. Andrés et al., Aproximación a la Historia social de la Iglesia Española contemporánea: 163-180. San Lorenzo de El Escorial: Ed. Biblioteca «La Ciudad de Dios» Real Monasterio de San Lorenzo de El Escorial.

Medina Arjona, E. 2009. La prensa/La presse. Jaén: Universidad de Jaén.

Mira Abad A. y Moreno Seco, M. 2004. «Maternidad y evolución de la identidad femenina en la España del siglo XX», en M. Santo (Coord.), La historia de las mujeres: una revisión historiográfica: 315-334. Valladolid: Universidad de Valladolid.

Muñoz López, P. 2001. Sangre, amor e interés. La familia en la España de la Restauración. Madrid: Marcial Pons.

Pascual Martínez, P. 2001. «Publicaciones periódicas eclesiásticas y religiosas de España entre los siglos XIX y XX». Hispania Sacra 107: 169-191.

Pelaz López, J. V. 2000. Caciques, apóstoles y periodistas. Medios de comunicación, poder y sociedad en Palencia (1898-1939). Valladolid: Universidad de Valladolid.

Pérez Ledesma, M. 2001. «Anticlericalismo y secularización en España», en A. Morales Moya (Coord.), La cultura. Las claves de la España del siglo Xx: 269-285. Madrid: España nuevo milenio.

Pérez-Picazo, M. T. 1986. Oligarquía urbana y campesinado en Murcia 1875-1902. Murcia: Academia Alfonso X el Sabio.

Perinat, A. y Marrades, M I. 1980. Mujer, prensa y sociedad en España, 1800-1939. Madrid: Centro de Investigaciones Sociológicas.

Poulat, E. 1977. Catholicisme, démocratie et socialisme. Paris: Casterman.

Robles Muñoz, C. 1989. «La diócesis de Cartagena durante la Restauración (18741900)». Murgetana 79: 69-105.

Hispania Sacra, LXVI

134, julio-diciembre 2014, 733-765, ISSN: 0018-215X, doi: 10.3989/hs.2014.067 
Roigé, X. 2011. «De la Restauración al franquismo. Modelos y prácticas familiares», en F. Chacón y J. Bestard (eds.), Familias. Historia de la sociedad española (siglos XIII-XXI): 667-741. Madrid: Cátedra.

Romero Domínguez, L. 2009. La buena prensa. Prensa católica en Andalucía durante la Restauración. Sevilla: Centro de Estudios Andaluces.

Ruiz Sánchez, J.-L. 2002. Prensa y propaganda católica (1832-1965). Sevilla: Universidad de Sevilla.

Ruiz Sánchez, J.-L. (Ed.) 2005. Catolicismo y comunicación en la historia contemporánea. Sevilla: Universidad de Sevilla.

Sáiz, M. D. 1990. Historia del periodismo en España. Los orígenes. El siglo XVIII. Madrid: Alianza.

Schulte, H. F. 1968. The spanish press 1470-1966: print, power and politics. Chicago: University of Illinois press.

Seoane, M. C. 1989. Historia del periodismo en España 2. El siglo XIX. Madrid: Alianza

Victoria Moreno, D. 1981. «La prensa católica en la Región Murciana durante el primer tercio del siglo XX». Murgetana 61: 51-79. 